\title{
Effects of Corrective Training on Drop Landing Ground Reaction Force Characteristics and Lower Limb Kinematics in Older Adults With Genu Valgus
}

Citation for published version (APA):

Jafarnezhadgero, A., Madadi-shad, M., Mccrum, C., \& Karamanidis, K. (2019). Effects of Corrective Training on Drop Landing Ground Reaction Force Characteristics and Lower Limb Kinematics in Older Adults With Genu Valgus: A Randomized Controlled Trial. Journal of Aging and Physical Activity, 27(1), 917. https://doi.org/10.1123/japa.2017-0315

Document status and date:

Published: 01/02/2019

DOI:

10.1123/japa.2017-0315

Document Version:

Publisher's PDF, also known as Version of record

Document license:

Taverne

Please check the document version of this publication:

- A submitted manuscript is the version of the article upon submission and before peer-review. There can be important differences between the submitted version and the official published version of record.

People interested in the research are advised to contact the author for the final version of the publication, or visit the DOI to the publisher's website.

- The final author version and the galley proof are versions of the publication after peer review.

- The final published version features the final layout of the paper including the volume, issue and page numbers.

Link to publication

\footnotetext{
General rights rights.

- You may freely distribute the URL identifying the publication in the public portal. please follow below link for the End User Agreement:

www.umlib.nl/taverne-license

Take down policy

If you believe that this document breaches copyright please contact us at:

repository@maastrichtuniversity.nl

providing details and we will investigate your claim.
}

Copyright and moral rights for the publications made accessible in the public portal are retained by the authors and/or other copyright owners and it is a condition of accessing publications that users recognise and abide by the legal requirements associated with these

- Users may download and print one copy of any publication from the public portal for the purpose of private study or research.

- You may not further distribute the material or use it for any profit-making activity or commercial gain

If the publication is distributed under the terms of Article $25 \mathrm{fa}$ of the Dutch Copyright Act, indicated by the "Taverne" license above, 


\title{
Effects of Corrective Training on Drop Landing Ground Reaction Force Characteristics and Lower Limb Kinematics in Older Adults With Genu Valgus: A Randomized Controlled Trial
}

\author{
AmirAli Jafarnezhadgero, Morteza Madadi-Shad, Christopher McCrum, and Kiros Karamanidis
}

\begin{abstract}
The aim of this study was to identify the effects of a corrective exercise program on landing ground reaction force characteristics and lower limb kinematics in older adults with genu valgus. A total of 26 older male adults with genu valgus were randomized into two groups. An experimental group conducted a 14-week corrective exercise program, whereas a control group did not perform any exercise. The experimental group displayed lower peak vertical, peak anterior and posterior, and peak medial ground reaction force components during the posttest compared with the pretest. The vertical loading rate, impulses, and free moment amplitudes were not statistically different between groups. In the experimental group, the peak knee abduction during the posttest was significantly smaller and the peak hip flexion angle was significantly greater than during the pretest. The authors suggest that this corrective exercise program may be a suitable intervention to improve landing ground reaction forces and lower limb kinematics in older male adults with genu valgus.
\end{abstract}

Keywords: free moment, impulse, loading rate, resistance training

Human lower limbs contribute to locomotion in multiple ways; acting as springs, as force absorbing dampers, or as actuators (Brown, O’Donovan, Hasselquist, Corner, \& Schiffman, 2016; Raynor, Yi, Abernethy, \& Jong, 2002). The progression of ground reaction forces (GRF) through the lower limbs during landing from a drop occurs in a distal to the proximal manner, suggesting that malalignment of the lower extremities might result in aberrant loading patterns to more proximal structures (Weidenhielm, Svensson, \& Broström, 1995). Specifically, frontal plane tibiofemoral joint alignment may affect injury mechanisms by selectively preloading or unloading specific tissues (Lerner, DeMers, Delp, \& Browning, 2015).

During movement, tibiofemoral joint malalignment often results in dynamic knee valgus (Almeida et al., 2016; Ishida, Yamanaka, Takeda, \& Aoki, 2014). Dynamic knee valgus is associated with anterior cruciate ligament (ACL) injury, patellofemoral pain (Hewett et al., 2005; Myer et al., 2015), and lateral compartment knee osteoarthritis (Butler, Barrios, Royer, \& Davis, 2011; Weidow, Tranberg, Saari, \& Kärrholm, 2006). Moreover, it has been demonstrated that for every one-degree change toward the valgus direction, an annual reduction of $23.4 \mathrm{~mm}^{3}$ in the total patella cartilage volume can be seen (Teichtahl, Wluka, \& Cicuttini, 2008). In adults aged from 50 to 79 years, valgus malalignment has shown a high association with an increased future risk of bone marrow lesions in the lateral knee compartment (Hayashi et al., 2012). Such knee joint degradation is likely related

Jafarnezhadgero and Madadi-Shad are with the Dept. of Physical Education and Sport Sciences, Faculty of Education Sciences and Psychology, University of Mohaghegh Ardabili, Ardabil, Iran. McCrum is with the Dept. of Human Movement Science, NUTRIM School of Nutrition and Translational Research in Metabolism, Maastricht University Medical Centre, Maastricht, The Netherlands; and the Institute of Movement and Sport Gerontology, German Sport University Cologne, Cologne, Germany. Karamanidis is with Sport and Exercise Science Research Centre, School of Applied Sciences, London South Bank University, London, United Kingdom. Address author correspondence to AmirAli Jafarnezhadgero at amiralijafarnezhad@gmail.com. to altered joint loading in dynamic knee valgus. One common method to assess dynamic knee valgus is drop landing tasks (Kagaya, Fujii, \& Nishizono, 2015). Decreased hip flexion, increased knee abduction, and increased knee external rotation were reported during single-limb drop landing in females with genu valgus (healthy females between the ages of 18-35) (Barrios et al., 2016). Less hip flexion at initial contact tends to lead to a more vertical position of the entire lower limb and may result in a stiffer landing strategy, as well as increased injury vulnerability (Chappell, Creighton, Giuliani, Yu, \& Garrett, 2007). The elevated injury risk may be due to an increased reliance on passive structures, specifically ligaments, to control deceleration (Pollard, Sigward, \& Powers, 2010). Previous studies have shown that landing with a high-impact force may be a risk factor for ACL injury (Chappell, Yu, Kirkendall, \& Garrett, 2002; Devita \& Skelly, 1992; Yu, Lin, \& Garrett, 2006). Furthermore, it is reported that an increase in posterior GRF requires an increase in knee extensor moment for balance, and this increase is a major contributor to higher peak proximal tibia anterior shear force that likely increases ACL loading (DeMorat, Weinhold, Blackburn, Chudik, \& Garrett, 2004; Yu \& Garrett, 2007; Yu et al., 2006). Therefore, based on the above findings, increased hip flexion and decreased knee abduction and external rotation during landing in genu valgus individuals should be regarded as targets for interventions in these patients (Barrios et al., 2016; Chappell et al., 2007). The treatment of knee misalignment might also help to reduce the GRF, vertical loading rate, impulses, and free moment (FM) which may, in turn, reduce the possibility of ACL injury, patellofemoral pain syndrome, and other disorders.

Traditional knee rehabilitation programs that focus on isolated quadriceps femoris or hamstring muscle group exercises, in conjunction with primarily uniplanar sagittal plane weight bearing tasks such as squats or forward lunges may be less effective in restoring the dynamic three dimensional knee-joint control required during different activities (Kean, Hinman, Wrigley, Lim, \& Bennell, 2017; Shaw, Williams, \& Chipchase, 2005). Also, conventional machine-based 
exercise equipment is often expensive, and not all physical therapists may be able to offer this to their patients at a low cost. Portable training devices, such as elastic resistance bands, can be used for effective strength training in healthy individuals (Jakobsen et al., 2012; Sundstrup et al., 2014), as well as in participants with musculoskeletal pain (Andersen et al., 2010) and may provide a potential alternative for individuals with genu valgus. During preinjury conditioning programs or postinjury rehabilitation, individuals with genu valgus may benefit from multi-planar resistive training to train ankle (Farley, Blickhan, Saito, \& Taylor, 1991), knee (Aboodarda, Page, \& Behm, 2016; Hostler et al., 2001), and hip (Aboodarda et al., 2016; Brandt et al., 2013) muscle groups for three dimensional knee-joint motion control, for which elastic resistance bands may be well suited.

The objective of this study was to investigate the effects of corrective training using elastic resistance bands on landing GRF characteristics and lower limb kinematics in older adults with genu valgus. It was hypothesized that (a) GRF components, including peak GRF components, in three dimensions, would be reduced and their time to peak (TTP) would be increased after corrective training, (b) vertical loading rate, impulses, and free moments would be reduced after corrective training, and that (c) increased peak hip flexion and decreased peak knee abduction and peak knee external rotation would be observed as a result of the training protocol.

\section{Methods}

\section{Study Design and Participants}

A randomized controlled design with equal group allocation was used (Figure 1). This study was approved by the Ardabil University of Medical Sciences and registered with the Iranian Registry of Clinical Trials (IRCT2016110230657N1). A power analysis $\left(\mathrm{G}^{*}\right.$ Power; Program written by Franz Faul, University of Kiel, Germany; [Faul, Erdfelder, Lang, \& Buchner, 2007]) determined that 26 participants were required to achieve a statistical power of .80 at an effect size of 0.80 with an alpha level of .05 in GRF variables. Distinct differences in biomechanical characteristics have been identified between females and males, and these differences occur in multiple planes of motion and across multiple joints (Bates, Nesbitt, Shearn, Myer, \& Hewett, 2016; Bruening, Frimenko, Goodyear, Bowden, \& Fullenkamp, 2015; Jenkins, Williams, Williams, Hefner, \& Welch, 2017). To exclude this potential influencing factor, only male older adults were recruited for the present study. About 26 older males with genu valgus were recruited in October 2016 from physical therapy clinics (in Hamadan City, Iran) and were randomized and allocated to the experimental group ( $\mathrm{EG} ; \mathrm{N}=13)$ or the control group $(\mathrm{CG} ; \mathrm{N}=13$ ) based on a list of random numbers. During the randomization process, a set of sealed, opaque envelopes were used to ensure the concealment of allocation. Each envelope contained a card indicating to which group the subject was allocated. Also, those evaluating the participants were not aware of the group allocation (i.e., blinding of assessors). Inclusion criteria were an age between 60 and 70 years, a tibial mechanical axis (TMA) $\leq 4^{\circ}$ from vertical, indicating alignment (Barrios et al., 2016), Q angle $>18^{\circ}$ (Magee, 2014), medial malleolus distance $>6 \mathrm{~cm}$ (Magee, 2014), and clearance from a doctor or physical therapist to participate. The degree of genu valgus was measured by the distance between the medial malleoli at the ankle (Magee, 2014), Q angle (Magee, 2014), and TMA while the participant was standing barefoot, with the feet together to assess whether their knees approximated.

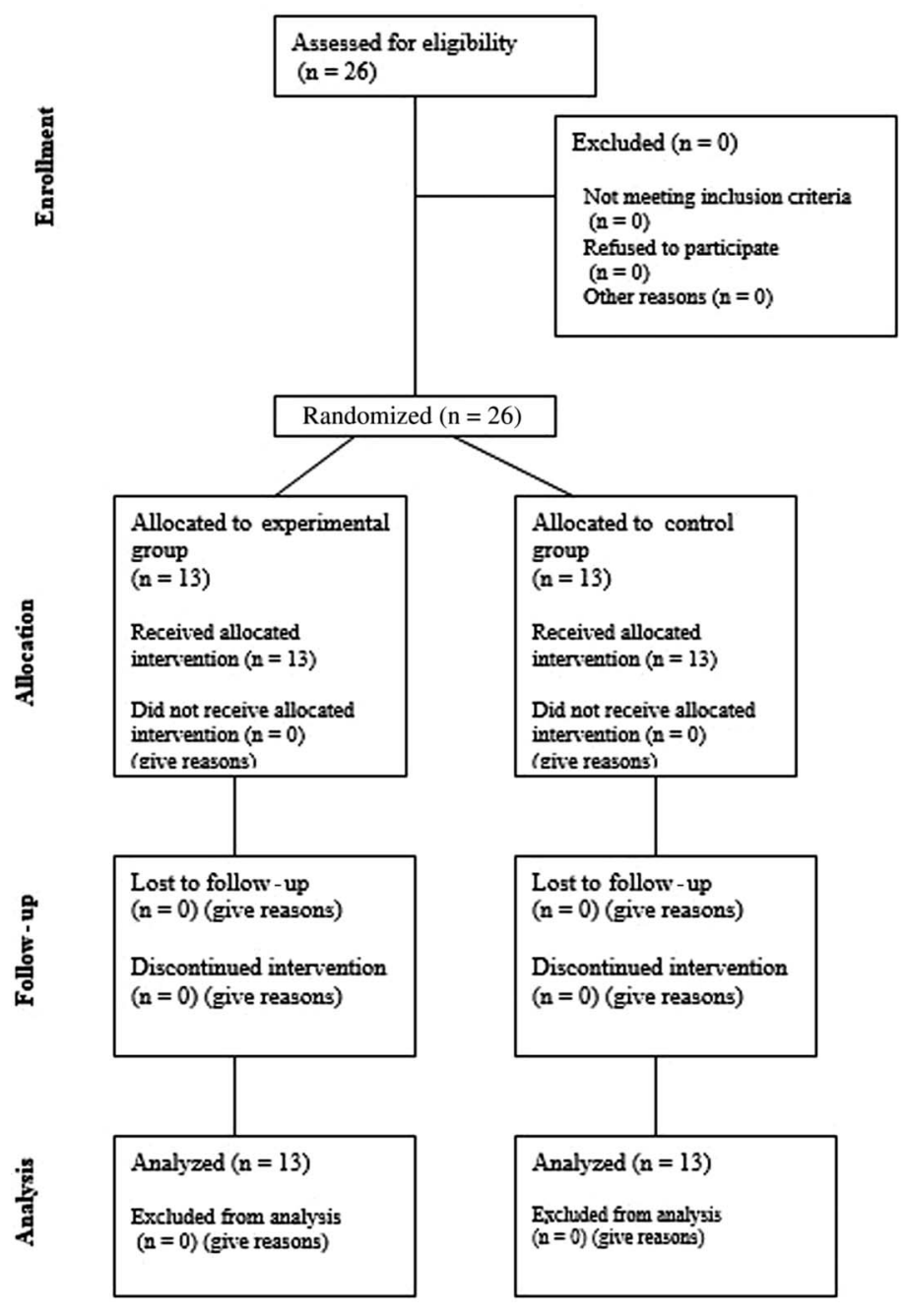

Figure 1 - Flow diagram of randomized control trial in this study.

If the knees were in contact, their TMA was clinically assessed with a calibrated digital inclinometer smartphone application (iPhone manufacturer, USA) (Barrios, Higginson, Royer, \& Davis, 2009; Vanwanseele, Parker, \& Coolican, 2009). Exclusion criteria were a history of knee injury or surgery, and other degenerative conditions such as severe knee osteoarthritis. The procedures were explained to the participants prior to obtaining informed consent in accordance with the Declaration of Helsinki.

The included participants reported demographic information including age, limb dominance, and injury history. The dominant leg was defined as the preferred leg used to kick a ball (Jafarnezhadgero, Shad, \& Majlesi, 2017). The Pepper Assessment Tool for Disability (Rejeski, Ip, Marsh, Miller, \& Farmer, 2008) was used for quantifying disability during preintervention (Table 1) and postintervention. The Pepper Assessment Tool for Disability self-administered questionnaire consists of 23 items that include a range of activities that assess mobility, activities of daily living, and instrumental activities of daily living. A lower disability score is associated with less disability during daily living.

\section{Drop Landing Assessment and Data Processing}

Participants performed five minutes of warm-up exercises to become familiar with the experimental environment and the 
Table 1 Mean (Standard Deviation) of the Participants' Anthropometric Measures and Disability Score During Pretest and Posttest Along With Change Values

\begin{tabular}{lccccccc}
\hline & \multicolumn{3}{c}{ Experimental Group } & & \multicolumn{3}{c}{ Control Group } \\
\cline { 2 - 3 } \cline { 7 - 8 } Variable & Pretest & Posttest & Change & & Pretest & Posttest & Change \\
\hline Number & 13 & 13 & 0 & & 13 & 13 & 0 \\
Age (years) & $63.9 \pm 2.2$ & - & - & & $64.0 \pm 2.6$ & - & - \\
Height (m) & $1.7 \pm 0.04$ & $1.7 \pm 0.06$ & $-0.0 \pm 0.03$ & & $1.69 \pm 0.05$ & $1.69 \pm 0.05$ & $0.00 \pm 0.01$ \\
Mass (kg) & $71.1 \pm 4.5$ & $71.2 \pm 4.9$ & $0.01 \pm 1.75$ & & $72.3 \pm 4.5$ & $72.3 \pm 4.8$ & $0.04 \pm 1.01$ \\
BMI (kg/m $\left.{ }^{2}\right)$ & $24.7 \pm 1.3$ & $24.8 \pm 1.4$ & $0.13 \pm 1.07$ & & $25.1 \pm 0.8$ & $25.1 \pm 0.8$ & $0.00 \pm 0.00$ \\
Q angle (degree) & $20.1 \pm 1.5$ & $19.4 \pm 1.1^{*}$ & $-0.8 \pm 0.7^{* *}$ & & $20.3 \pm 1.2$ & $20.3 \pm 1.2$ & $0.00 \pm 0.00^{* *}$ \\
TMA (degree) & $2.9 \pm 1.2$ & $3.6 \pm 1.0^{*}$ & $0.7 \pm 0.8^{* *}$ & & $2.7 \pm 1.1$ & $2.7 \pm 1.1$ & $0.00 \pm 0.00^{* *}$ \\
Malleolus distance $(\mathrm{cm})$ & $6.8 \pm 0.8$ & $6.5 \pm 0.6^{*}$ & $-0.30 \pm 0.44^{* *}$ & & $6.8 \pm 0.7$ & $6.8 \pm 0.6$ & $-0.01 \pm 0.03^{* *}$ \\
Disability score & $73.1 \pm 3.8$ & $64.5 \pm 5.8^{*}$ & $-8.54 \pm 4.56^{* *}$ & & $73.4 \pm 3.7$ & $73.5 \pm 3.1$ & $0.08 \pm 0.86^{* *}$ \\
\hline
\end{tabular}

TMA = tibial mechanical axis; BMI = body mass index.

*Significant within group difference. ${ }^{*}$ Significant difference between control and experimental groups.

landing task. Following this, 16 reflective markers (14-mm diameter) were placed bilaterally on specific anatomical landmarks on the lower limbs of the participants, according to the guidelines of the Vicon Plug-In-Gait marker set. Participants then performed up to three landing trials to familiarize themselves with the landing task. After the familiarization trials, a researcher instructed the participant to complete five bilateral drop landing trials. The same researcher instructed every participant throughout this study to ensure consistent verbal cues. The participants were instructed to execute a double-leg landing task by stepping off a platform (height $=30 \mathrm{~cm}$ ) and landing barefoot with each foot on each force plate; they were asked to employ their natural landing style (Yeow, Lee, \& Goh, 2010). A trial was considered successful when the participant stepped off the platform (without an upward and/or forward jump action, confirmed with kinematic data) and adopted a stable landing posture (Yeow et al., 2010). Each participant repeated the procedure until five successful landings were recorded. Any fatigue effects were mitigated by each subject resting for at least $60 \mathrm{~s}$ between each of landing trials (Niu, Wang, He, Fan, \& Zhao, 2011).

Position coordinate data of the markers were collected using six Vicon cameras at a sampling rate of $200 \mathrm{~Hz}$ (Motion Analysis Corp., Vicon Motion Capture System, Oxford, UK). In addition, two Kistler force plates (1000 Hz; Type 9281, Kistler Instrument AG, Winterthur, Switzerland) were used to record the GRF components during bilateral drop landing. Motion analysis and force plate systems were synchronized and monitored with Nexus 1.7.5 software (Oxford, UK). Kinematic data were low-pass filtered with a $15-\mathrm{Hz}$ cutoff. The GRF data were filtered using a fourth-order low-pass Butterworth filter with a $50-\mathrm{Hz}$ cutoff frequency. We temporally normalized the landing phase to 101 points using cubic spline interpolation (MatlabR2012a).

The GRF values were recorded along vertical $(z)$, mediolateral $(x)$, and anteroposterior $(y)$ directions as follows: The peak of the vertical GRF $\left(\mathrm{Fz}_{\mathrm{MAX}}\right)$; the positive $\left(\mathrm{Fx}_{\mathrm{MAX}}\right)$ and negative $\left(\mathrm{Fx}_{\mathrm{MIN}}\right)$ peaks of the mediolateral curve; and the positive peak in the anteroposterior direction (Fy FAX $_{\text {M }}$ ). These parameters and their TTP have previously been used to evaluate normal and pathological human drop landing (Carcia, Kivlan, \& Scibek, 2012; Hargrave, Carcia, Gansneder, \& Shultz, 2003; Podraza \& White, 2010). Loading rate was defined as the slope between the initiation and $\mathrm{Fz}_{\mathrm{MAX}}$ of the vertical GRF curve (Munro, Miller, \&
Fuglevand, 1987). Impulse was also computed, defined using the trapezoidal integration method for $x, y$, and $z$ axes as follows (Robertson, Caldwell, Hamill, Kamen, \& Whittlesey, 2013):

$$
\text { Impulse }=\Delta t\left[\left(\frac{F 1+F n}{2}\right)+\sum_{i=2}^{n-1} F i\right] .
$$

Free moment of the foot was calculated as follows (Almosnino, Kajaks, \& Costigan, 2009):

$$
\text { Free moment }=\mathrm{Mz}+(\mathrm{Fx} \times \mathrm{COPy})-(\mathrm{Fy} \times \mathrm{COPx}),
$$

where $\mathrm{Mz}$ is the moment about the vertical axis; $\mathrm{x}$ and $\mathrm{y}$ are the horizontal components of the center of pressure (COP); Fx and Fy are the horizontal components of the GRF.

For the FM curve, the first peak (negative; abductor moment) and the second peak (positive; adductor moment) were recorded. All GRF and FM values were normalized with respect to the Body Weight and Body Weight $\times$ Height, respectively. Lower limb joints angles (peak knee abduction, peak knee external rotation, and peak hip flexion) were computed using functional hip joint center and mean helical knee axis models (Besier, Sturnieks, Alderson, \& Lloyd, 2003) within the software Bodybuilder (Vicon Peak, Oxford, United Kingdom).

\section{Corrective Exercise Intervention}

Elastic resistance bands (Thera-Band ${ }^{\circledR}$, Akron, $\mathrm{OH}$ ) ranging from very low to very high resistance (yellow, red, green, blue, black, and silver) were used in this intervention. The 1-m long elastic bands were stretched to twice their resting length prior to each exercise (Andersen et al., 2010; Patterson, Jansen, Hogan, \& Nassif, 2001). During the first two weeks of the intervention, the EG performed stretching exercises for the hip adductor, biceps femoris, and tensor fascia latae muscles, performed in four sets of $30 \mathrm{~s}$ for each movement (Pollock et al., 1998), based on recommendations for corrective training interventions (Clark \& Lucett, 2010). Following these first two weeks of stretch training, the EG performed resistance band exercises for both legs three times per week for fourteen weeks (i.e., 42 strength training sessions). The participants were familiarized with the exercises prior to training. Each exercise session consisted of a general warm-up of $10 \mathrm{~min}$, followed by a resistance training session (35-40 $\mathrm{min}$ ) and was 
completed with a cool-down routine. Following an adaptation phase of 4 weeks using low external resistance (yellow TheraBand $\AA$; unless the participant was obviously unchallenged, one set of 14 repetitions per exercise [Franzke et al., 2015; Page \& Ellenbecker, 2005]), exercise intensity was progressively increased by adapting the resistance of the elastic band (based on the TheraBand $\AA$ force-elongation table) (Page \& Ellenbecker, 2005) from yellow to red, and further to black. In addition, the exercise volume was extended by increasing the number of sets from one to two. Rate of progression was based on individual improvements (band color was changed if participants were able to perform 16 repetitions or more in the second set) and reported that they were below seven on the OMNI resistance for active muscle scale ( 0 extremely easy to 10 extremely hard [Lagally \& Robertson, 2006]). The movement velocity during exercises was very low. The intervention in the EG was conducted individually in a physiotherapy clinic, with every session being supervised by a physiotherapist to ensure correct technique or to modify the exercise or the progression to suit the participants' needs. After the intervention, participants of the EG were reevaluated following the same procedures as the first evaluation. The reevaluation was scheduled six days after the final intervention session to guarantee that acute physiological responses to training did not interfere with the measurements (Clarkson \& Hubal, 2002). The CG did not perform any exercise and were reevaluated after 16 weeks. All participants were asked not to participate in any other forms of sports or exercise during the intervention period. The training exercises for the EG are described in Table 2 and illustrated in Figure 2.

\section{Statistical Analysis}

Normality of the distribution for outcome measures was confirmed by the Shapiro-Wilk test. Statistical within and between-group differences were assessed by paired sample t tests and independent sample t tests, respectively. In addition, the effect sizes $(d)$ were computed as a ratio of the mean difference divided by the pooled standard deviation, with effect sizes of $0.2,0.5$, and 0.8 indicating small, moderate, and large effect sizes, respectively. Statistical significance was set at $p<.05$. Data were analyzed using the SPSS software (version 16; SPSS Inc., Chicago, IL). All values are reported as mean (standard deviation).

\section{Results}

No significant between-group differences were found at baseline for all examined variables $(p>.05)$ (Tables 1 and 3; Figure 3). The reduction of $\mathrm{Q}$ angle $(p=.002 ; \mathrm{d}=2.13)$, malleolus distance $(p=.036 ; \mathrm{d}=1.23)$, and disability score $(p<.001 ; \mathrm{d}=3.23)$ in EG were significantly greater than that of the CG (Table 1). Moreover, the increment in TMA in the EG was significantly higher than the $\mathrm{CG}$ after the training intervention (Table 1).

Ground reaction forces variables for both pretest and posttest during drop landing are presented in Table 3 and Figure 4. The EG displayed lower $\mathrm{Fz}_{\mathrm{MAX}}, \mathrm{Fx}_{\mathrm{MAX}}, \mathrm{Fx}_{\mathrm{MIN}}$, and Fy $\mathrm{MAX}$ by approximately $29 \%(p=.008 ; d=1.27), 71 \%(p=.006 ; d=1.42), 19 \%$ $(p=.021 ; d=1.06)$, and $36 \%(p<.001 ; d=2.13)$, respectively, during posttest compared with the pretest. For the CG, GRF

\section{Table 2 The Training Exercises for the Experimental Group}

\begin{tabular}{|c|c|}
\hline Movements & Description \\
\hline Hip adductor stretching & $\begin{array}{l}\text { In the seated position bend both legs and put the feet together. Allow the knees to lower to the ground to increase } \\
\text { the stretch. }\end{array}$ \\
\hline Tensor fascia latae stretching & $\begin{array}{l}\text {-In a seated position, pull the knee across and in toward the body. } \\
\text {-Start in a standing position and cross the right leg behind the left leg. The right foot should be to the outside of } \\
\text { the left foot, with both feet pointing forward. Without tilting forward from the hips, lean the weight of your body } \\
\text { over the right foot. Keep the hips pressing forward. Allow the left hip to drop slightly until a stretch is felt in their } \\
\text { outer right hip. }\end{array}$ \\
\hline Biceps femoris stretching & In a supine position, pull the knee into extension and internal rotation. \\
\hline Hip abductor strength training & $\begin{array}{l}\text { Four exercises: in the side-lying position with limb to be strengthened on top (Figure 2, A1); in the standing } \\
\text { position (Figure } 2, \text { A } 2 \text { ); side-stepping with elastic resistance in the distal region of the thigh (Figure } 2 \text {, A3) } \\
\text { (Kamonseki, Gonçalves, Liu, \& Júnior, 2016); and the exercise was performed seated on massage table adjusted } \\
\text { to position the hip at } 60^{\circ} \text { (Figure } 2, \text { A4; from this position, the participant was instructed to activate the hip } \\
\text { abductors while keeping the knee at about } 90^{\circ} \text { ) }\end{array}$ \\
\hline Invertor strength training & The invertors were strengthened in side-lying position (Figure 2B) (Kamonseki et al., 2016). \\
\hline
\end{tabular}

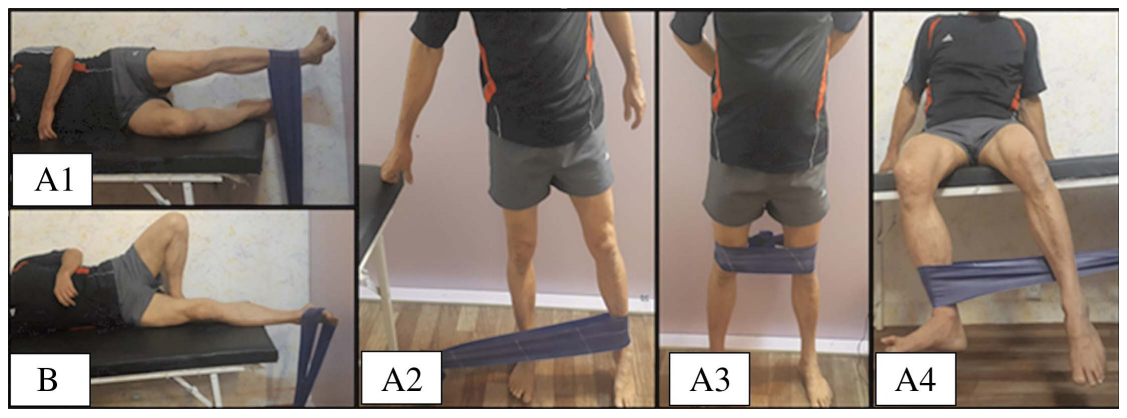

Figure 2 - Foot and hip exercises used in the intervention. Hip abductor strength training (A1, A2, A3 and A4). Foot invertor strength training (B). 
Table 3 Mean (Standard Deviation) of the Pretest, Posttest, and Change Values of GRF of z, x, and y Axes (\%BW), TTP of GRF Components (ms), Vertical Loading Rate (BW/s), Impulses (Imp) and FM for Both Groups

\begin{tabular}{|c|c|c|c|c|c|c|c|}
\hline \multirow[b]{2}{*}{ Variable } & \multirow[b]{2}{*}{ Component } & \multicolumn{3}{|c|}{ Experimental Group } & \multicolumn{3}{|c|}{ Control Group } \\
\hline & & Pretest & Posttest & Change & Pretest & Posttest & Change \\
\hline \multicolumn{8}{|l|}{ GRF } \\
\hline $\mathrm{Fz}$ & $\mathrm{Fz}_{\text {MAX }}$ & $249 \pm 88$ & $176 \pm 27 *$ & $-73 \pm 82 * *$ & $202 \pm 82$ & $215 \pm 73$ & $13 \pm 51 * *$ \\
\hline \multirow[t]{2}{*}{$\mathrm{Fx}$} & $\mathrm{Fx}_{\text {MAX }}$ & $45 \pm 37$ & $13 \pm 8 *$ & $-32 \pm 35^{* *}$ & $33 \pm 30$ & $38 \pm 32$ & $5 \pm 26^{* *}$ \\
\hline & $\mathrm{Fx}_{\mathrm{MIN}}$ & $-85 \pm 17$ & $-69 \pm 12^{*}$ & $-16 \pm 22$ & $-98 \pm 48$ & $-84 \pm 17$ & $-14 \pm 48$ \\
\hline Fy & Fy $_{\text {MAX }}$ & $44 \pm 9$ & $28 \pm 6^{*}$ & $-16 \pm 10$ & $36 \pm 26$ & $29 \pm 14$ & $-7 \pm 19$ \\
\hline \multicolumn{8}{|l|}{ TTP } \\
\hline $\mathrm{Fz}$ & $\mathrm{Fz}_{\text {MAX }}$ & $63 \pm 13$ & $59 \pm 21$ & $-3 \pm 25$ & $60 \pm 13$ & $63 \pm 13$ & $4 \pm 13$ \\
\hline \multirow[t]{2}{*}{$\mathrm{Fx}$} & $\mathrm{Fx}_{\text {MAX }}$ & $44 \pm 15$ & $42 \pm 14$ & $-2 \pm 24$ & $38 \pm 14$ & $44 \pm 15$ & $5 \pm 17$ \\
\hline & $\mathrm{Fx}_{\mathrm{MIN}}$ & $16 \pm 4$ & $13 \pm 5^{*}$ & $-2 \pm 4$ & $17 \pm 10$ & $15 \pm 4$ & $-1 \pm 12$ \\
\hline Fy & Fy $_{\text {MAX }}$ & $19 \pm 20$ & $13 \pm 17$ & $-6 \pm 29$ & $32 \pm 13$ & $21 \pm 20$ & $-11 \pm 23$ \\
\hline Loading rate & Vertical & $428 \pm 221$ & $324 \pm 103$ & $-104 \pm 213$ & $382 \pm 185$ & $401 \pm 188$ & $18 \pm 87$ \\
\hline \multirow[t]{3}{*}{ Impulse } & $\operatorname{Imp} \mathrm{x}$ & $7.0 \pm 0.9$ & $6.4 \pm 1.9$ & $-0.6 \pm 2.0$ & $6.9 \pm 0.7$ & $7.2 \pm 1.1$ & $0.1 \pm 1.1$ \\
\hline & $\operatorname{Imp} y$ & $5.9 \pm 1.4$ & $5.0 \pm 4.9$ & $-0.9 \pm 4.8$ & $5.1 \pm 2.2$ & $5.5 \pm 1.2$ & $0.5 \pm 1.7$ \\
\hline & $\operatorname{Imp} \mathrm{z}$ & $33.4 \pm 4.6$ & $34.2 \pm 15.3$ & $0.9 \pm 16.6$ & $28.6 \pm 5.1$ & $30.2 \pm 4.6$ & $1.4 \pm 6.4$ \\
\hline \multirow[t]{2}{*}{ FM } & Positive peak & $0.02 \pm 0.02$ & $0.01 \pm 0.01$ & $-0.01 \pm 0.01$ & $0.02 \pm 0.01$ & $0.01 \pm 0.02$ & $-0.01 \pm 0.02$ \\
\hline & Negative peak & $-0.07 \pm 0.02$ & $-0.06 \pm 0.02$ & $-0.01 \pm 0.03$ & $-0.07 \pm 0.03$ & $-0.06 \pm 0.03$ & $-0.01 \pm 0.03$ \\
\hline
\end{tabular}

$\mathrm{GRF}=$ ground reaction force; $\mathrm{TTP}=$ time to peak; $\mathrm{FM}=$ free moment.

*Significant within group difference. ${ }^{* *}$ Significant difference between control and experimental groups.
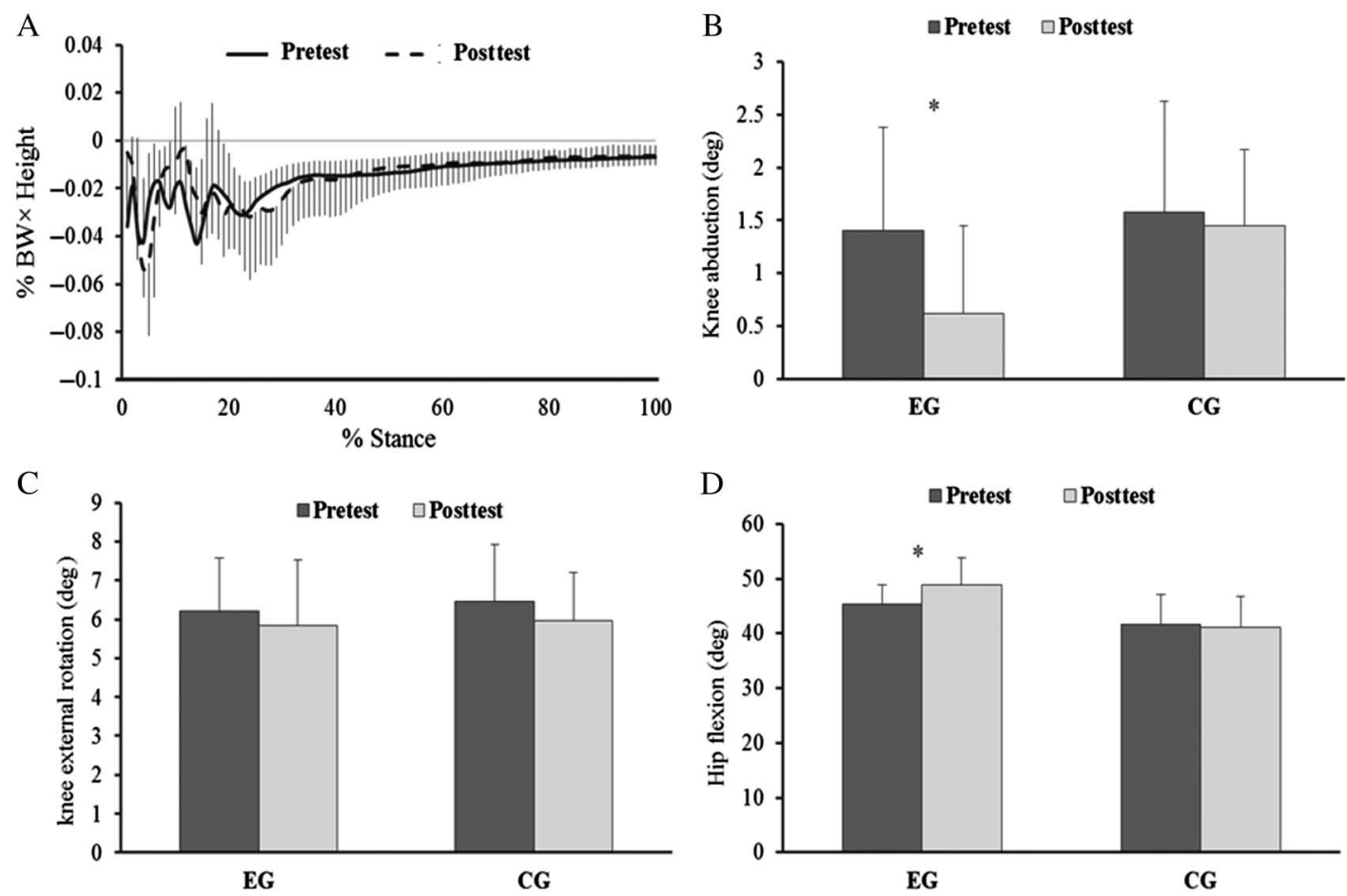

Figure 3 - (A) Time-normalized traces of the free moment, (B) peak knee abduction angle, (C) peak knee external rotation, and (D) peak hip flexion angle for the EG during pre- and posttest. Note: All data are means (standard deviations). $\mathrm{EG}=$ experimental group; $\mathrm{CG}=\mathrm{control}$ group; $\mathrm{BW}$ indicates body weight. *Significant difference $(p<.05)$.

amplitudes were similar between pretest and posttest $(p>.05)$. The TTP for both groups can be seen in Table 3. In EG, the TTP for $\mathrm{Fx}_{\mathrm{MIN}}$ (by $19 \% ; p=.044 ; d=0.53$ ) during posttest were significantly smaller than that of pretest. Other TTP variables in EG were not significantly different between pretraining and posttraining $(p>.05)$. For the $\mathrm{CG}$, no significant group differences in the TTP variables were found $(p>.05)$. No significant within or between group differences were found for the vertical 


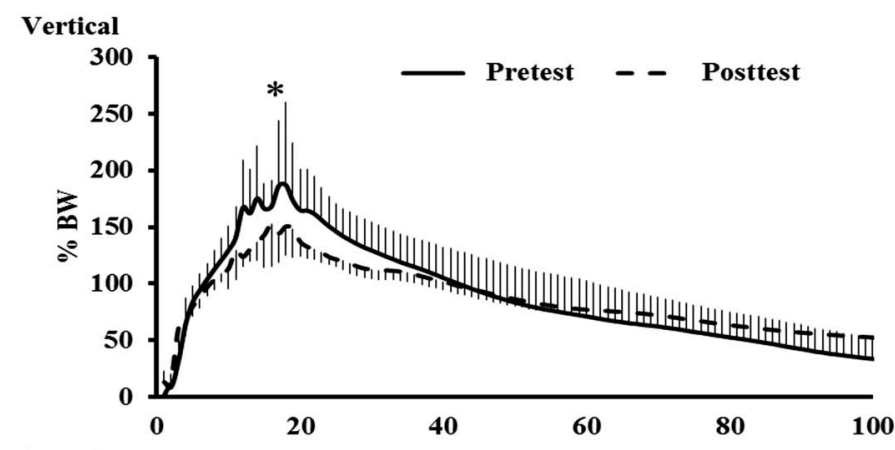

Anterior

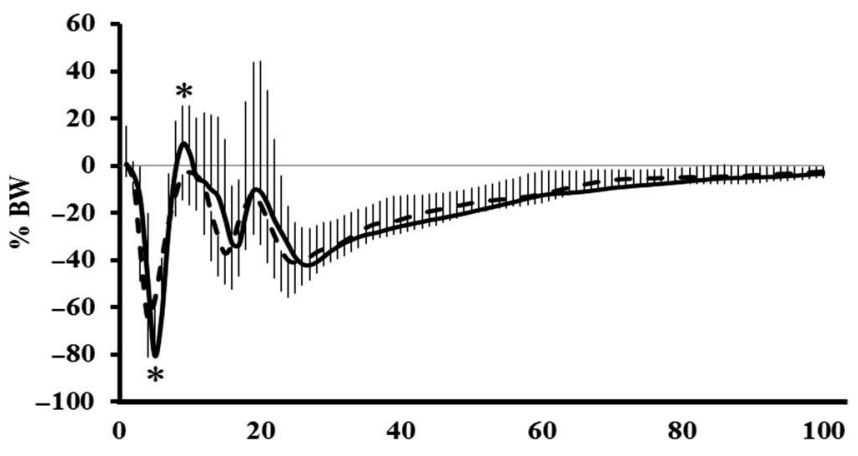

Medial

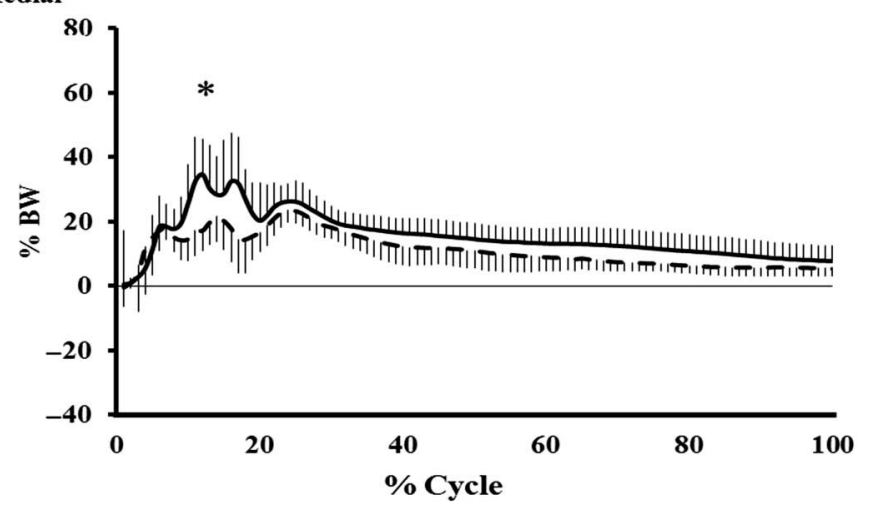

Figure 4 - Time-normalized traces of the ground reaction forces of experimental group (in pre- and posttest) during bilateral drop landing. Data are mean (standard deviation). BW=body weight. *Significant difference in positive or negative peak values $(p<.05)$.

loading rate (Table 3), impulse variables ( $x, y$, and $z$ ) (Table 3), and peak positive and negative FM amplitudes (Table 3 and Figure 4a) $(p>.05)$.

The peak knee abduction and external rotation and also peak hip flexion angles for both groups during pretest and posttest can be seen in Figure 3. In EG, the peak knee abduction during posttest $(0.62 \pm 0.83)$ was significantly smaller than that of the pretest $(1.40 \pm 0.98$; by $56 \% ; p=.005 ; d=0.86$; Figure $3 b)$. Also, in EG, the peak hip flexion angle during posttest (48.92 \pm $4.89)$ was significantly greater than that at pretest $(45.37 \pm 3.43$; by $8 \% ; p=.011 ; d=0.85$; Figure $3 \mathrm{~d})$. Peak knee external rotation in EG was not significantly different between pretraining (6.22 \pm $1.36)$ and post $(5.83 \pm 1.70)$ training $(p=.337$; Figure $3 c)$. For the $\mathrm{CG}$, no significance within group differences in the peak knee abduction $(p=.345$; Figure $3 \mathrm{~b})$, external rotation $(p=.159$; Figure $3 c)$, and peak hip flexion $(p=.284$; Figure $3 d)$ angles was found.

\section{Discussion}

The objective of this study was to investigate the effects of corrective training using elastic resistance bands on landing GRF and kinematic characteristics in older individuals with genu valgus. To our knowledge, this is the first study to observe a decreased $\mathrm{Fz}_{\mathrm{MAX}}$ during drop landing after corrective training in participants with genu valgus. Our first hypothesis, that GRF components in three dimensions would be reduced and their TTP would be increased after corrective training, was partly confirmed, as lower peak vertical, peak anterior and posterior, and peak medial GRF components (by 29\%, 71\%, 19\%, and 36\%, respectively) were found for the EG during the posttest compared with the pretest. However, the TTP for $\mathrm{Fx}_{\mathrm{MIN}}$ was significantly smaller posttest compared with pretest in the EG. Our second hypothesis, that vertical loading rate, impulses, and free moments would be reduced after corrective training, could not be confirmed, as no significant differences in the EG were found after the training. Finally, our third hypothesis, that increased peak hip flexion and decreased peak knee abduction and peak knee external rotation would be observed as a result of the training protocol, was partly confirmed, as the peak knee abduction during posttest was significantly smaller than that of the pretest and the peak hip flexion angle during posttest was significantly higher than that at pretest. However, no change was observed in peak knee external rotation.

In the current study, the intervention led to a reduction in peak vertical, peak anterior and posterior, and peak medial GRF components. A lower $\mathrm{Fz}_{\mathrm{MAX}}$ along with lower disability score and lower static knee joint valgus alignment after corrective training may indicate that the corrective training enabled more effective bilateral drop landing. This may be explained by the increased degrees of hip flexion in the EG (see Figure 3), as well as potentially less cocontraction (Podraza \& White, 2010), providing resilience to compression forces. This finding is potentially important, as a decreased hip flexion has previously been reported during drop landing in individuals with genu valgus (Barrios et al., 2016). Less hip flexion at initial contact tends to lead to a more vertical position of the entire lower limb and may result in a stiffer landing strategy, as well as increased injury vulnerability (Chappell et al., 2007). In addition to a decreased $\mathrm{Fz}_{\mathrm{MAX}}$, we found that $\mathrm{Fy}_{\text {MAX }}$ (peak medial GRF) decreased after corrective training (Table 3 and Figure 4). This coincided with a reduction in peak knee abduction angle. A potential increase in hip abductor strength may explain this finding (Dai, Heinbaugh, Ning, \& Zhu, 2014; Turban, Culas, \& Deley, 2014). Since excessive hip adduction during landing can cause the knee joint to move medially and increase the knee abduction angle (Powers, 2003, 2010), increased hip abductor strength can create an internal hip abduction moment to decrease the medial displacement of the knee and knee abduction angle (as seen in Figure 3). Therefore, landing with a small knee abduction angle may possibly decrease mediolateral GRF, as well as ACL loading and the risk of ACL injuries (Hewett et al., 2005). Based on our results, corrective training could decrease peak vertical and medial GRF, increase peak hip flexion angle and decrease peak knee abduction angles during drop landing in older adults with genu valgus. Finally, considering the $\mathrm{Fx}_{\mathrm{MAX}}$ (peak anterior GRF) and $\mathrm{Fx}_{\mathrm{MIN}}$ (peak posterior GRF) results, it is important to note that the current resistance band training intervention found significant reductions in these variables (Table 3 and Figure 4). Previous studies have reported that an increase in posterior GRF requires an increase in knee extensor moment for balance, and this increase in knee extensor moment is the main contributor to higher peak proximal tibia anterior shear force that probably increases ACL 
loading (DeMorat et al., 2004; Yu \& Garrett, 2007; Yu et al., 2006). Therefore, reduction of $\mathrm{Fx}_{\mathrm{MIN}}$ after corrective training may have a clinical importance for older adults with genu valgus.

Previous work has demonstrated that genu valgus is associated with earlier peak anteroposterior GRF timing during impact absorption phase of crossover cutting (Nyland \& Caborn, 2004). However, TTP of GRF components in older adults with genu valgus was not evaluated in previous studies. In the present study, the TTP values of the EG on all GRF components (except for $\mathrm{Fx}_{\mathrm{MIN}}$ ) were not changed after the training intervention. Therefore, the current exercise intervention appears not to have been a sufficient stimulus to encourage a favorable change in the TTP of GRF variables. Similarly, no significant changes were observed in bilateral loading rate and impulse (all axes) after the corrective training intervention. Despite intervention-related reductions in impact peak $\left(\mathrm{Fz}_{\mathrm{MAX}}\right)$, the loading rate remained similar. Therefore, based on our findings, the corrective training protocol used in the current study may provide some degree of shock attenuation by reduction of impact peak, but this finding should be interpreted with caution, due to the lack of significant change in loading rate.

The results of the present study showed that similar peak positive and negative FM amplitudes in both CG and EG during preintervention and postintervention. FM has a relationship with applied torsional loads during translations of the body (Milner, Davis, \& Hamill, 2006). In comparison to the vertical, anteroposterior, and mediolateral components of the GRF, FM around the vertical axis is a better indicator for identifying the vulnerability of the body tissues (Li, Wang, Crompton, \& Gunther, 2001; Umberger, 2008). However, our results did not show any significant difference in change values of peak negative and positive FM amplitudes between EG and CG after the corrective training program.

Several methodological limitations of the current study should be acknowledged. Our data in the present study were restricted to the GRF characteristics and lower limb kinematics. However, threedimensional kinematics and kinetics of lower and upper extremity, as well as the trunk, are considered by many to be a critical factor in landing induced injuries (Ali, Robertson, \& Rouhi, 2014; Blackburn \& Padua, 2008). Therefore, future work should also consider the influence of training on such factors. Secondly, males were exclusively used for this study, and it is not clear how such training interventions would affect the landing kinetics and kinematics in female participants. Furthermore, comparison of electromyographical activity (Iida, Kanehisa, Inaba, \& Nakazawa, 2011) across these populations before and after corrective training could provide further insight into the intervention effects, and may be interesting with respect to clinical implications.

\section{Conclusions}

The current study found that a 16 -week corrective training intervention using resistance bands led to a reduction in $\mathrm{Fz}_{\mathrm{MAX}}$, $\mathrm{Fx}_{\mathrm{MAX}}$, and $\mathrm{Fx}_{\mathrm{MIN}}$ of dominant lower limb during bilateral drop landing in older individuals with genu valgus disorder. In addition, the peak knee abduction during posttest was significantly smaller than that of pretest and the peak hip flexion angle during posttest was significantly smaller than that of pretest. Taken together, the results may indicate a reduced injury risk for the intervention group.

\section{Acknowledgments}

The authors gratefully thank all volunteers who participated and cooperated in this study. This research did not receive any specific grant from funding agencies in the public, commercial, or not-for-profit sectors. C. McCrum is funded by the Kootstra Talent Fellowship awarded by the Centre for Research Innovation, Support and Policy (CRISP) and by the NUTRIM Graduate Programme, both of Maastricht University Medical Center. The authors have no conflicts of interest to disclose. Ethical Approval: This study was approved by the Ardabil University of Medical Sciences and registered with the Iranian Registry of Clinical Trials (IRCT2016110230657N1). All procedures performed in studies involving human participants were in accordance with the ethical standards of the institutional and/or national research committee and with the 1964 Helsinki Declaration and its later amendments or comparable ethical standards. Informed consent was obtained from all individual participants included in the study.

\section{References}

Aboodarda, S.J., Page, P.A., \& Behm, D.G. (2016). Muscle activation comparisons between elastic and isoinertial resistance: A meta-analysis. Clinical Biomechanics, 39, 52-61. PubMed ID: 27681867 doi:10.1016/ j.clinbiomech.2016.09.008

Ali, N., Robertson, D.G.E., \& Rouhi, G. (2014). Sagittal plane body kinematics and kinetics during single-leg landing from increasing vertical heights and horizontal distances: Implications for risk of noncontact ACL injury. The Knee, 21(1), 38-46. PubMed ID: 23274067 doi:10.1016/j.knee.2012.12.003

Almeida, G.P., Silva, A.P., França, F.J., Magalhães, M.O., Burke, T.N., \& Marques, A.P. (2016). Q-Angle in patellofemoral pain: relationship with dynamic knee valgus, hip abductor torque, pain and function. Revista Brasileira de Ortopedia (English Edition), 51(2), 181-186. doi:10.1016/j.rboe.2016.01.010

Almosnino, S., Kajaks, T., \& Costigan, P.A. (2009). The free moment in walking and its change with foot rotation angle. Sports Medicine, Arthroscopy, Rehabilitation, Therapy \& Technology, 1(1), 19. doi: 10.1186/1758-2555-1-19

Andersen, L.L., Andersen, C.H., Mortensen, O.S., Poulsen, O.M., Bjørnlund, I.B.T., \& Zebis, M.K. (2010). Muscle activation and perceived loading during rehabilitation exercises: Comparison of dumbbells and elastic resistance. Physical Therapy, 90(4), 538-549. PubMed ID: 20133444 doi:10.2522/ptj.20090167

Barrios, J.A., Heitkamp, C.A., Smith, B.P., Sturgeon, M.M., Suckow, D.W., \& Sutton, C.R. (2016). Three-dimensional hip and knee kinematics during walking, running, and single-limb drop landing in females with and without genu valgum. Clinical Biomechanics, 31, 7-11. PubMed ID: 26515886 doi:10.1016/j.clinbiomech.2015. 10.008

Barrios, J.A., Higginson, J.S., Royer, T.D., \& Davis, I.S. (2009). Static and dynamic correlates of the knee adduction moment in healthy knees ranging from normal to varus-aligned. Clinical Biomechanics, 24(10), 850-854. PubMed ID: 19703728 doi:10.1016/j.clinbiomech. 2009.07.016

Bates, N.A., Nesbitt, R.J., Shearn, J.T., Myer, G.D., \& Hewett, T.E. (2016). Sex-based differences in knee ligament biomechanics during robotically simulated athletic tasks. Journal of Biomechanics, 49(9), $1429-1436$.

Besier, T.F., Sturnieks, D.L., Alderson, J.A., \& Lloyd, D.G. (2003). Repeatability of gait data using a functional hip joint centre and a mean helical knee axis. Journal of Biomechanics, 36(8), 1159-1168. PubMed ID: 12831742 doi:10.1016/S0021-9290(03)00087-3

Blackburn, J.T., \& Padua, D.A. (2008). Influence of trunk flexion on hip and knee joint kinematics during a controlled drop landing. Clinical Biomechanics, 23(3), 313-319. PubMed ID: 18037546 doi:10.1016/ j.clinbiomech.2007.10.003 
Brandt, M., Jakobsen, M.D., Thorborg, K., Sundstrup, E., Jay, K., \& Andersen, L.L. (2013). Perceived loading and muscle activity during hip strengthening exercises: Comparison of elastic resistance and machine exercises. International Journal of Sports Physical Therapy, 8(6), 811. PubMed ID: 24377067

Brown, T., O'Donovan, M., Hasselquist, L., Corner, B., \& Schiffman, J.M. (2016). Lower limb flexion posture relates to energy absorption during drop landings with soldier-relevant body borne loads. Applied Ergonomics, 52, 54-61. PubMed ID: 26360194 doi:10.1016/j.apergo. 2015.06.004

Bruening, D.A., Frimenko, R.E., Goodyear, C.D., Bowden, D.R., \& Fullenkamp, A.M. (2015). Sex differences in whole body gait kinematics at preferred speeds. Gait and Posture, 41(2), 540-545.

Butler, R.J., Barrios, J.A., Royer, T., \& Davis, I.S. (2011). Frontal-plane gait mechanics in people with medial knee osteoarthritis are different from those in people with lateral knee osteoarthritis. Physical Therapy, 91(8), 1235-1243. doi:10.2522/ptj.20100324

Carcia, C.R., Kivlan, B.R., \& Scibek, J.S. (2012). Time to peak force is related to frontal plane landing kinematics in female athletes. Physical Therapy in Sport, 13(2), 73-79. PubMed ID: 22498147 doi:10.1016/ j.ptsp.2011.06.003

Chappell, J.D., Creighton, R.A., Giuliani, C., Yu, B., \& Garrett, W.E. (2007). Kinematics and electromyography of landing preparation in vertical stop-jump risks for noncontact anterior cruciate ligament injury. The American Journal of Sports Medicine, 35(2), 235-241. PubMed ID: 17092926 doi:10.1177/0363546506294077

Chappell, J.D., Yu, B., Kirkendall, D.T., \& Garrett, W.E. (2002). A comparison of knee kinetics between male and female recreational athletes in stop-jump tasks. The American Journal of Sports Medicine, 30(2), 261-267. PubMed ID: 11912098. doi:10.1177/ 03635465020300021901

Clark, M., \& Lucett, S. (2010). NASM essentials of corrective exercise training. Philadelphia: Jones \& Bartlett Learning.

Clarkson, P.M., \& Hubal, M.J. (2002). Exercise-induced muscle damage in humans. American Journal of Physical Medicine \& Rehabilitation, 81(11), S52-S69. doi:10.1097/00002060-200211001-00007

Dai, B., Heinbaugh, E.M., Ning, X., \& Zhu, Q. (2014). A resistance band increased internal hip abduction moments and gluteus medius activation during pre-landing and early-landing. Journal of Biomechanics, 47(15), 3674-3680. doi:10.1016/j.jbiomech.2014.09.032

DeMorat, G., Weinhold, P., Blackburn, T., Chudik, S., \& Garrett, W. (2004). Aggressive quadriceps loading can induce noncontact anterior cruciate ligament injury. The American Journal of Sports Medicine, 32(2), 477-483. PubMed ID: 14977677 doi:10.1177/ 0363546503258928

Devita, P., \& Skelly, W.A. (1992). Effect of landing stiffness on joint kinetics and energetics in the lower extremity. Medicine Science Sports \& Exercise, 24(1), 108-115.

Farley, C.T., Blickhan, R., Saito, J., \& Taylor, C.R. (1991). Hopping frequency in humans: A test of how springs set stride frequency in bouncing gaits. Journal of Applied Physiology, 71(6), 2127-2132. PubMed ID: 1778902 doi:10.1152/jappl.1991.71.6.2127

Faul, F., Erdfelder, E., Lang, A.-G., \& Buchner, A. (2007). G* Power 3: A flexible statistical power analysis program for the social, behavioral, and biomedical sciences. Behavior Research Methods, 39(2), 175-191. PubMed ID: 17695343 doi:10.3758/BF03193146

Franzke, B., Halper, B., Hofmann, M., Oesen, S., Pierson, B., Cremer, A., . . Tosevska, A. (2015). The effect of six months of elastic band resistance training, nutritional supplementation or cognitive training on chromosomal damage in institutionalized elderly. Experimental Gerontology, 65, 16-22. PubMed ID: 25747997 doi:10.1016/j.exger. 2015.03.001
Hargrave, M.D., Carcia, C.R., Gansneder, B.M., \& Shultz, S.J. (2003). Subtalar pronation does not influence impact forces or rate of loading during a single-leg landing. Journal of Athletic Training, 38(1), 18. PubMed ID: 12937467

Hayashi, D., Englund, M., Roemer, F.W., Niu, J., Sharma, L., Felson, D.T., . . L Lewis, C.E. (2012). Knee malalignment is associated with an increased risk for incident and enlarging bone marrow lesions in the more loaded compartments: The MOST study. Osteoarthritis and Cartilage, 20(11), 1227-1233. PubMed ID: 22874524 doi:10.1016/ j.joca.2012.07.020

Hewett, T.E., Myer, G.D., Ford, K.R., Heidt, R.S., Colosimo, A.J., McLean, S.G., . . . Succop, P. (2005). Biomechanical measures of neuromuscular control and valgus loading of the knee predict anterior cruciate ligament injury risk in female athletes a prospective study. The American Journal of Sports Medicine, 33(4), 492-501. PubMed ID: 15722287 doi:10.1177/0363546504269591

Hostler, D., Schwirian, C.I., Campos, G., Toma, K., Crill, M.T., Hagerman, G.R., . . Staron, R.S. (2001). Skeletal muscle adaptations in elastic resistance-trained young men and women. European Journal of Applied Physiology, 86(2), 112-118. PubMed ID: 11822469 doi: $10.1007 / \mathrm{s} 004210100495$

Iida, Y., Kanehisa, H., Inaba, Y., \& Nakazawa, K. (2011). Activity modulations of trunk and lower limb muscles during impact-absorbing landing. Journal of Electromyography and Kinesiology, 21(4), 602-609. PubMed ID: 21549617 doi:10.1016/j.jelekin.2011.04.001

Ishida, T., Yamanaka, M., Takeda, N., \& Aoki, Y. (2014). Knee rotation associated with dynamic knee valgus and toe direction. The Knee, 21(2), 563-566. PubMed ID: 23290175 doi:10.1016/j.knee.2012. 12.002

Jafarnezhadgero, A.A., Shad, M.M., \& Majlesi, M. (2017). Effect of foot orthoses on the medial longitudinal arch in children with flexible flatfoot deformity: A three-dimensional moment analysis. Gait \& Posture, 55, 75-80. PubMed ID: 28419877 doi:10.1016/j.gaitpost. 2017.04.011

Jakobsen, M.D., Sundstrup, E., Andersen, C.H., Bandholm, T., Thorborg, K., Zebis, M.K., \& Andersen, L.L. (2012). Muscle activity during knee-extension strengthening exercise performed with elastic tubing and isotonic resistance. International Journal of Sports Physical Therapy, 7(6), 606

Jenkins, W.L., Williams, D.B., Williams, K., Hefner, J., \& Welch, H. (2017). Sex differences in total frontal plane knee movement and velocity during a functional single-leg landing. Physical Therapy in Sport, 24, 1-6.

Kagaya, Y., Fujii, Y., \& Nishizono, H. (2015). Association between hip abductor function, rear-foot dynamic alignment, and dynamic knee valgus during single-leg squats and drop landings. Journal of Sport and Health Science, 4(2), 182-187. doi:10.1016/j.jshs.2013. 08.002

Kamonseki, D.H., Gonçalves, G.A., Liu, C.Y., \& Júnior, I.L. (2016). Effect of stretching with and without muscle strengthening exercises for the foot and hip in patients with plantar fasciitis: A randomized controlled single-blind clinical trial. Manual Therapy, 23, 76-82.

Kean, C.O., Hinman, R.S., Wrigley, T.V., Lim, B.-W., \& Bennell, K.L. (2017). Impact loading following quadriceps strength training in individuals with medial knee osteoarthritis and varus alignment. Clinical Biomechanics, 42, 20-24. PubMed ID: 28068520 doi:10. 1016/j.clinbiomech.2017.01.002

Lagally, K.M., \& Robertson, R.J. (2006). Construct validity of the OMNI resistance exercise scale. The Journal of Strength \& Conditioning Research, 20(2), 252-256. PubMed ID: 16686549

Lerner, Z.F., DeMers, M.S., Delp, S.L., \& Browning, R.C. (2015). How tibiofemoral alignment and contact locations affect predictions of 
medial and lateral tibiofemoral contact forces. Journal of Biomechanics, 48(4), 644-650. doi:10.1016/j.jbiomech.2014.12.049

Li, Y., Wang, W., Crompton, R.H., \& Gunther, M.M. (2001). Free vertical moments and transverse forces in human walking and their role in relation to arm-swing. Journal of Experimental Biology, 204(1), 47-58

Magee, D.J. (2014). Orthopedic physical assessment. Alberta, Canada: Elsevier Health Sciences.

Milner, C.E., Davis, I.S., \& Hamill, J. (2006). Free moment as a predictor of tibial stress fracture in distance runners. Journal of Biomechanics, 39(15), 2819-2825. PubMed ID: 16289078 doi:10.1016/j.jbiomech. 2005.09.022

Munro, C.F., Miller, D.I., \& Fuglevand, A.J. (1987). Ground reaction forces in running: A reexamination. Journal of Biomechanics, 20(2), 147-155. PubMed ID: 3571295 doi:10.1016/0021-9290(87)90306-X

Myer, G.D., Ford, K.R., Di Stasi, S.L., Foss, K.D.B., Micheli, L.J., \& Hewett, T.E. (2015). High knee abduction moments are common risk factors for patellofemoral pain (PFP) and anterior cruciate ligament (ACL) injury in girls: Is PFP itself a predictor for subsequent ACL injury? British Journal of Sports Medicine, 49(2), 118-122. PubMed ID: 24687011 doi:10.1136/bjsports-2013-092536

Niu, W., Wang, Y., He, Y., Fan, Y., \& Zhao, Q. (2011). Kinematics, kinetics, and electromyogram of ankle during drop landing: A comparison between dominant and non-dominant limb. Human Movement Science, 30(3), 614-623. PubMed ID: 21439665 doi:10. 1016/j.humov.2010.10.010

Nyland, J., \& Caborn, D. (2004). Physiological coxa varus-genu valgus influences internal knee and ankle joint moments in females during crossover cutting. Knee Surgery, Sports Traumatology, Arthroscopy, 12(4), 285-293. PubMed ID: 14618320 doi:10.1007/s00167-0030430-3

Page, P., \& Ellenbecker, T. (2005). Strength band training. USA: Human Kinetics.

Patterson, R.M., Jansen, C.W.S., Hogan, H.A., \& Nassif, M.D. (2001). Material properties of thera-band tubing. Physical Therapy, 81(8), 1437-1445. PubMed ID: 11509073 doi:10.1093/ptj/81.8.1437

Podraza, J.T., \& White, S.C. (2010). Effect of knee flexion angle on ground reaction forces, knee moments and muscle co-contraction during an impact-like deceleration landing: Implications for the non-contact mechanism of ACL injury. The Knee, 17(4), 291-295. PubMed ID: 20303276 doi:10.1016/j.knee.2010.02.013

Pollard, C.D., Sigward, S.M., \& Powers, C.M. (2010). Limited hip and knee flexion during landing is associated with increased frontal plane knee motion and moments. Clinical Biomechanics, 25(2), 142-146. PubMed ID: 19913961 doi:10.1016/j.clinbiomech.2009.10.005

Pollock, M.L., Gaesser, G.A., Butcher, J.D., Després, J.-P., Dishman, R.K., Franklin, B.A., \& Garber, C.E. (1998). ACSM position stand. Medicine \& Science in Sports \& Exercise, 30(6), 975-991.

Powers, C.M. (2003). The influence of altered lower-extremity kinematics on patellofemoral joint dysfunction: A theoretical perspective. Journal of Orthopaedic \& Sports Physical Therapy, 33(11), 639-646. PubMed ID: 14669959 doi:10.2519/jospt.2003.33.11.639

Powers, C.M. (2010). The influence of abnormal hip mechanics on knee injury: A biomechanical perspective. Journal of Orthopaedic \& Sports Physical Therapy, 40(2), 42-51. PubMed ID: 20118526 doi:10.2519/jospt.2010.3337

Raynor, A.J., Yi, C.J., Abernethy, B., \& Jong, Q.J. (2002). Are transitions in human gait determined by mechanical, kinetic or energetic factors?
Human Movement Science, 21(5), 785-805. doi:10.1016/S01679457(02)00180-X

Rejeski, W.J., Ip, E.H., Marsh, A.P., Miller, M.E., \& Farmer, D.F. (2008). Measuring disability in older adults: The International Classification System of Functioning, Disability and Health (ICF) framework. Geriatrics \& Gerontology International, 8(1), 48-54. PubMed ID: 18713189 doi:10.1111/j.1447-0594.2008.00446.x

Robertson, G., Caldwell, G., Hamill, J., Kamen, G., \& Whittlesey, S. (2013). Research methods in biomechanics (2nd ed.). USA: Human Kinetics.

Shaw, T., Williams, M.T., \& Chipchase, L.S. (2005). Do early quadriceps exercises affect the outcome of ACL reconstruction? A randomised controlled trial. Australian Journal of Physiotherapy, 51(1), 9-17. PubMed ID: 15748120 doi:10.1016/S0004-9514(05)70048-9

Sundstrup, E., Jakobsen, M., Andersen, C., Bandholm, T., Thorborg, K., Zebis, M., \& Andersen, L. (2014). Evaluation of elastic bands for lower extremity resistance training in adults with and without musculo-skeletal pain. Scandinavian Journal of Medicine \& Science in Sports, 24(5), e353-e359. PubMed ID: 25138624 doi:10.1111/ sms. 12187

Teichtahl, A., Wluka, A., \& Cicuttini, F. (2008). Frontal plane knee alignment is associated with a longitudinal reduction in patella cartilage volume in people with knee osteoarthritis. Osteoarthritis and Cartilage, 16(7), 851-854. PubMed ID: 18194873 doi:10.1016/ j.joca.2007.12.002

Turban, C., Culas, C., \& Deley, G. (2014). Effects of a short-term resistance program using elastic bands or weight machines in cardiac rehabilitation. Science \& Sports, 29(3), 143-149. doi:10.1016/j. scispo.2013.07.005

Umberger, B.R. (2008). Effects of suppressing arm swing on kinematics, kinetics, and energetics of human walking. Journal of Biomechanics, 41(11), 2575-2580. PubMed ID: 18621376 doi:10.1016/j.jbiomech. 2008.05.024

Vanwanseele, B., Parker, D., \& Coolican, M. (2009). Frontal knee alignment: three-dimensional marker positions and clinical assessment. Clinical Orthopaedics and Related Research, 467(2), 504-509. PubMed ID: 18841432 doi:10.1007/s11999-008-0545-4

Weidenhielm, L., Svensson, O., \& Broström, L.-Å. (1995). Surgical correction of leg alignment in unilateral knee osteoarthrosis reduces the load on the hip and knee joint bilaterally. Clinical Biomechanics, 10(4), 217-221. PubMed ID: 11415556 doi:10.1016/0268-0033(95) 91401-Y

Weidow, J., Tranberg, R., Saari, T., \& Kärrholm, J. (2006). Hip and knee joint rotations differ between patients with medial and lateral knee osteoarthritis: Gait analysis of 30 patients and 15 controls. Journal of Orthopaedic Research, 24(9), 1890-1899. PubMed ID: 16838360 doi:10.1002/jor.20194

Yeow, C., Lee, P., \& Goh, J. (2010). Sagittal knee joint kinematics and energetics in response to different landing heights and techniques. The Knee, 17(2), 127-131. PubMed ID: 19720537 doi:10.1016/ j.knee.2009.07.015

Yu, B., \& Garrett, W.E. (2007). Mechanisms of non-contact ACL injuries. British Journal of Sports Medicine, 41(Suppl. 1), i47-i51.

Yu, B., Lin, C.-F., \& Garrett, W.E. (2006). Lower extremity biomechanics during the landing of a stop-jump task. Clinical Biomechanics, 21(3), 297-305. PubMed ID: 16378667 doi:10.1016/j.clinbiomech.2005. 11.003 